\title{
Frontal sinus osteoplastic flap: is it relevant today? Archana Shah ${ }^{\mathrm{a}}$, Moushumi Sengupta ${ }^{\mathrm{b}}$, Vedula P. Saha ${ }^{\mathrm{c}}$, Somnath Saha ${ }^{\mathrm{a}}$
}

aDepartment of ENT and Head and Neck Surgery, Calcutta National Medical College, bepartments of Plastic Surgery, 'ENT and Head and Neck Surgery, R.G. Kar Medical College, Kolkata, West Bengal, India

Correspondence to Archana Shah, MS (ENT), c/o Sundaram, 91 Sarat Chaterjee Road, Barat, Lake Town, Kolkata 700089, West Bengal India, Tel: 033-24426091;

e-mail: archanashah01@rediffmail.com

Received 30 September 2015

Accepted 2 June 2016

The Egyptian Journal of Otolaryngology 2018, 34:229-233

\begin{abstract}
In the present era where frontal sinus surgery is synonymous with functional endoscopic sinus surgery, we present a case series comprising six cases of varied frontal sinus pathology that were managed with an external approach using an osteoplastic flap technique. The study was carried out in the ENT Department of Calcutta National Medical College, a tertiary care center in Kolkata. A unilateral osteoplastic flap approach was adopted in three cases, of which two were reported as osteomas and one was that of inverted papilloma. Bicoronal osteoplastic flap was raised in another group, which included a case of communited fracture of the anterior wall of the frontal sinus with obvious cosmetic facial deformity, a case of fracture of the posterior wall of the frontal sinus with traumatic cerebrospinal fluid rhinorrhea with pneumoencephalus, and a case of plasmacytoma of the frontal sinus. The mean follow-up period ranged from 1 to 3 years. There was no recurrence of disease and no significant postoperative complications have been reported during the follow-up period so far.
\end{abstract}

\section{Keywords:}

external approach, frontal sinus, frontal sinus obliteration, osteoplastic flap

Egypt J Otolaryngol 34:229-233

(C) 2018 The Egyptian Journal of Otolaryngology

$1012-5574$

\section{Introduction}

Frontal sinus surgery has come a long way since eighteenth century when the first frontal sinus procedure was described in 1750 [1]. More than two centuries have passed since then and the management of frontal sinus disorders is still a matter of debate. Its variable anatomy and proximity to critical structures such as the orbit and the anterior skull base make the frontal sinus surgery different from the relatively more straightforward surgical approaches to the rest of the paranasal sinuses. Although recent advances in imaging and endoscopic techniques have led to resurgence in intranasal endoscopic procedures, in certain frontal sinus diseases such as frontal/frontoethmoid osteoma, posterior table erosion, failed endoscopic approaches, laterally placed disease, and absent or distorted intranasal landmarks, open approach is still the modality of choice [2]. Time and again, osteoplastic anterior wall approach to the frontal sinus has proved to be one of the most effective, simple, and reliable procedures with excellent success rate and good cosmesis [3].

\section{Case history}

After taking a relevant and informed consent from the patients or guardian (whichever applicable), each patient was treated under general anesthesia. Both cases of osteoma were managed with a unilateral osteoplastic flap raised by means of a supraorbital incision that extended to the level of nasal process of the frontal bone, followed by elevation of the musculocutaneous flap superiorly (Fig. $1 \mathrm{a}-\mathrm{c}$ and Table 1).

The osteoma was then chiseled out, clearing the frontal sinus, whereas in case of inverted papilloma the unilateral osteoplastic flap was raised in continuity with the Weber-Ferguson incision. In three cases, the flaps were raised using bicoronal incision made behind the hairline and just anterior to the tragus bilaterally. The dissection proceeded beneath the galea, with elevation of the frontalis muscle. The scalp flap was pulled caudally on both sides, leaving behind the periosteum and the bone, thus preserving the supraorbital and supratrochlear vascular bundle. A template of the frontal sinus excised from the occipitofrontal plain radiograph, preserved in a disinfectant solution was positioned on the root of the nose and borders of the frontal sinus were estimated. The pericranium was incised and elevated using blunt as well as sharp dissection up to the supraorbital ridge and over the root of the nose slightly, being pedicled caudally at the bone. The anterior wall of the frontal sinus was downfractured and elevated as inferiorly based bony flap after joining the burr holes drilled along the outline of the frontal sinus with an $\sim 30^{\circ}$ angulation directed toward the

\footnotetext{
This is an open access journal, and articles are distributed under the terms of the Creative Commons Attribution-NonCommercial-ShareAlike 4.0 License, which allows others to remix, tweak, and build upon the work non-commercially, as long as appropriate credit is given and the new creations are licensed under the identical terms.
} 
Figure 1
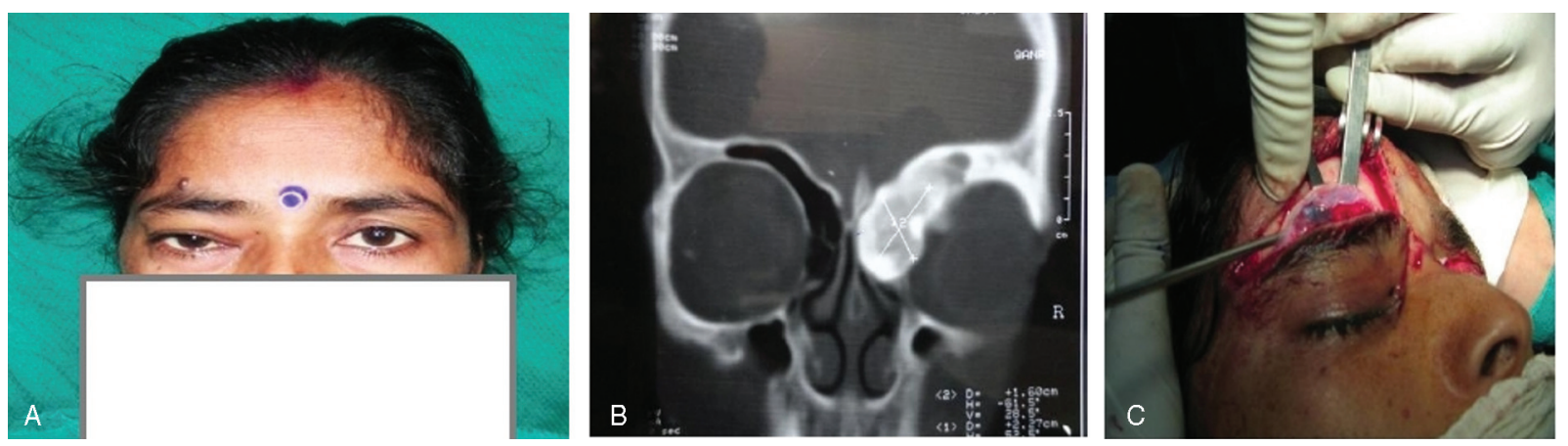

(a) Right supraorbital swelling (osteoma). (b) Radiodense shadow occupying the right frontal sinus. (c) Downfractured anterior wall of the frontal sinus after elevation of right-sided musculocutaneous flap (unilateral) through a right supraorbital skin incision to gain access to the osteoma.

Table 1 Brief history, positive features on examination and radiology, diagnosis, and management of the cases

\begin{tabular}{|c|c|c|c|c|c|c|}
\hline Case & $\begin{array}{c}\text { Age } \\
\text { (years) }\end{array}$ & Sex & Chief complaints & Computed tomography finding & Diagnosis & $\begin{array}{l}\text { Treatment } \\
\text { modality }\end{array}$ \\
\hline 1 & 40 & Female & $\begin{array}{l}\text { Swelling near the right eyelid } \\
\text { just above the medial } \\
\text { canthus }\end{array}$ & $\begin{array}{l}\text { Radiodense opacity in the right } \\
\text { frontal sinus }\end{array}$ & $\begin{array}{l}\text { Frontal } \\
\text { osteomaFig.1a-c }\end{array}$ & $\begin{array}{l}\text { Osteoplastic flap } \\
\quad \text { (unilateral) }\end{array}$ \\
\hline 2 & 59 & Male & $\begin{array}{l}\text { Supraorbital swelling and } \\
\text { proptosis of the left eye, pain, } \\
\text { recent-onset diminished } \\
\text { vision }\end{array}$ & $\begin{array}{l}\text { Homogenous opacity, left frontal } \\
\text { sinus with erosion of the roof and } \\
\text { the medial of the wall left orbit }\end{array}$ & PlasmacytomaFig.2a-c & $\begin{array}{l}\text { Osteoplastic flap } \\
\text { (bicoronal) }\end{array}$ \\
\hline 3 & 38 & Male & CSF rhinorrhea & $\begin{array}{c}\text { Fracture of the posterior table of } \\
\text { the left frontal sinus and } \\
\text { pneumoencephalus }\end{array}$ & $\begin{array}{l}\text { CSF leak with fracture } \\
\text { of the frontal sinus } \\
\text { Fig.3 }\end{array}$ & $\begin{array}{l}\text { Osteoplastic flap } \\
\text { (bicoronal) }\end{array}$ \\
\hline 4 & 22 & Male & Left supraorbital swelling & $\begin{array}{l}\text { Radiodense opacity in the left } \\
\text { frontal sinus }\end{array}$ & $\begin{array}{l}\text { Frontoethmoid } \\
\text { osteoma }\end{array}$ & $\begin{array}{l}\text { Osteoplastic flap } \\
\quad \text { (unilateral) }\end{array}$ \\
\hline 5 & 52 & Male & $\begin{array}{l}\text { Unilateral proptosis, nasal } \\
\text { mass discharging sinus with } \\
\text { maggots }\end{array}$ & $\begin{array}{l}\text { Opacified ipsilateral maxillary, } \\
\text { ethmoids and frontal, intracranial } \\
\text { but extradural extent }\end{array}$ & Inverted papilloma & $\begin{array}{l}\text { Osteoplastic flap } \\
\text { (modified } \\
\text { Weber-Ferguson) }\end{array}$ \\
\hline 6 & 30 & Male & Facial disfigurement & $\begin{array}{l}\text { Comminuted fracture of the } \\
\text { anterior table of the frontal sinus }\end{array}$ & $\begin{array}{l}\text { RTA with fracture of } \\
\text { the frontal sinus }\end{array}$ & $\begin{array}{l}\text { Osteoplastic flap } \\
\text { (bicoronal) }\end{array}$ \\
\hline
\end{tabular}

CSF, cerebrospinal fluid; RTA, road traffic accident.

frontal sinus maintained to ensure a wide surface for the later replacement of the bony flap.

\section{Discussion}

External approach accounts for about 5\% [4] of all frontal sinus surgeries, with the osteoplastic flaps usually being reserved for those disorders that cannot be successfully treated endonasally $[5,6]$. This approach provides an optimal view of the entire frontal sinus and allows complete microscopic removal of the mucosa as well as obliteration of frontal sinus with abdominal fat [7]. The various surgical approaches to deal with frontal sinus disorders can be either external, intranasal, or combined depending on the type and extent of disease. External approach includes frontal sinus trephination, frontoethmoidectectomy (Lynch-Howarth) or osteoplastic bone flap. Intranasal approach for all practical purpose means endoscopic sinus surgery ranging from Messerklinger technique with special emphasis on mucosa preservation to more radical endoscopic approaches such as the modified Lothrop $[8,9]$ (frontal sinus drill out) and balloon sinuplasty [10]. Availability of such a wide variety of treatment modalities makes the optimal management protocol for frontal sinus disorders a matter of conflict and debate. In addition, no single approach has been able to fulfill the criteria for the modality of choice in terms of excellent results, no recurrence or residual disease, minimal morbidity, short hospital stay, uneventful long-term postoperative course, and good cosmesis in cases of extensive disease and extrasinus involvement.

In 1884, Ogston [11] described trephination through the anterior table to evacuate the frontal sinus and placed a tube in the nasofrontal duct. However, this technique had high failure rate due to frontonasal duct stenosis [12]. Riedel's procedure in which the anterior 
table was removed to clear disease was marred by postoperative cosmetic forehead deformity and thus abandoned. In 1908, Knapp [13] performed an extensive ethmoidectomy through the medial orbital wall, leaving the anterior wall of the frontal sinus intact but removing the diseased mucosa and enlarging the frontonasal duct. Lothrop [14], resected the frontal sinus floor between the frontal recess and the intersinus septum along with the upper aspect of the nasal septum after an ethmoidectomy using an external approach. Lynch [15] and Howarth [16], entered the frontal sinus through an external approach through the medial orbital wall. The osteoplastic bone flap procedure was described by Tato and Bergaglio [7], which permitted an optimal view of the frontal sinus allowing complete removal of the mucosa, followed by obliteration of the sinus with abdominal fat with no cosmetic deformity. Goodale and Montgomery claimed excellent success rates with uneventful postoperative recovery using osteoplastic flaps for various indications in their case series reported in 1958 and 1976. The procedure gained popularity and became the standard procedure during that period $[17,18]$.

In our case series of different pathologies involving the frontal sinus, the use of an endoscope was not feasible, given the nature of the disease, and hence the osteoplastic flap technique was resorted to as the procedure of choice. In both cases of frontal osteoma, wide exposure of the frontal sinus was the key to complete removal of the disease. Although endoscopic modified Lothrop alone [19] has been used for removal of osteoma, the literature is suggestive of its role being limited to cases in which the lesion is medial to a virtual plane through the lamina papyracea and in cases of attachment in the lower portion of the posterior wall of the sinus [20].
Besides being time consuming, transnasal removal of osteomas is convenient to perform only in spongious type as compared with ivory variety [21-23]. The possibility of incomplete resection, especially in cases of very large tumors [24], and the difficult endoscopic approach in cases of osteoma(s) located far lateral in the frontal sinus or having a widely based attachment to the base of the skull make external approach a preferred treatment modality [21-25].

In case of plasmacytoma, the patient had presented with painful and deteriorating vision with increasing proptosis, as the mass in the left frontal sinus was compressing the globe following erosion of the medial orbital wall and the orbital roof (Fig. $2 \mathrm{a}$ and b). Opening up the frontal sinus under direct vision helped in disease clearance, thereby reducing the pain and resulting in orbital decompression with improved vision (Fig. 2c). In cerebrospinal fluid rhinorrhea, the patient had a posterior table fracture with pnemoencephalus (Fig. 3), which could not be dealt with using the endoscopic approach. The fractured segment was removed under direct vision and dural defect repaired. The fifth case was that of inverted papilloma in which the mass was also filling up the ipsilateral frontal sinus with radiologic evidence of minimal intracranial but extradural extent. In this case, the modified Weber-Ferguson [26] incision was made for proper exposure and best possible access. In the sixth case of comminuted fracture of the anterior table, the osteoplastic flap technique helped in wide exposure of the area of defect so that it could be repaired by means of plate-screw fixation following obliteration of the sinus. The use of a radiographic plate to outline the frontal sinus as was described by Becker [27] was a great advantage to safely elevate the bony flap. The estimate of the outline prevents complications such as injury to the meninges or brain tissue while ensuring a

Figure 2
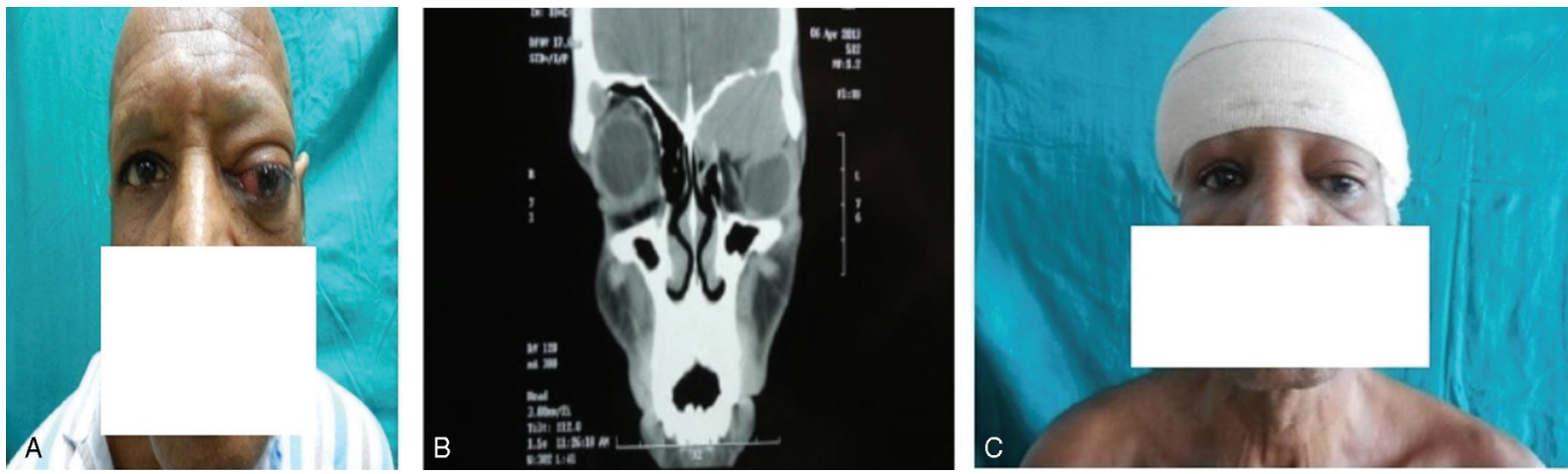

(a) Supraorbital swelling and proptosis of the left eye (plasmacytoma). (b) Homogenous opacity of the left frontal sinus with erosion of the roof and medial wall of the left orbit. (c) Early postoperative appearance of the patient after external approach through osteoplastic flap (bicoronal). 


\section{Figure 3}

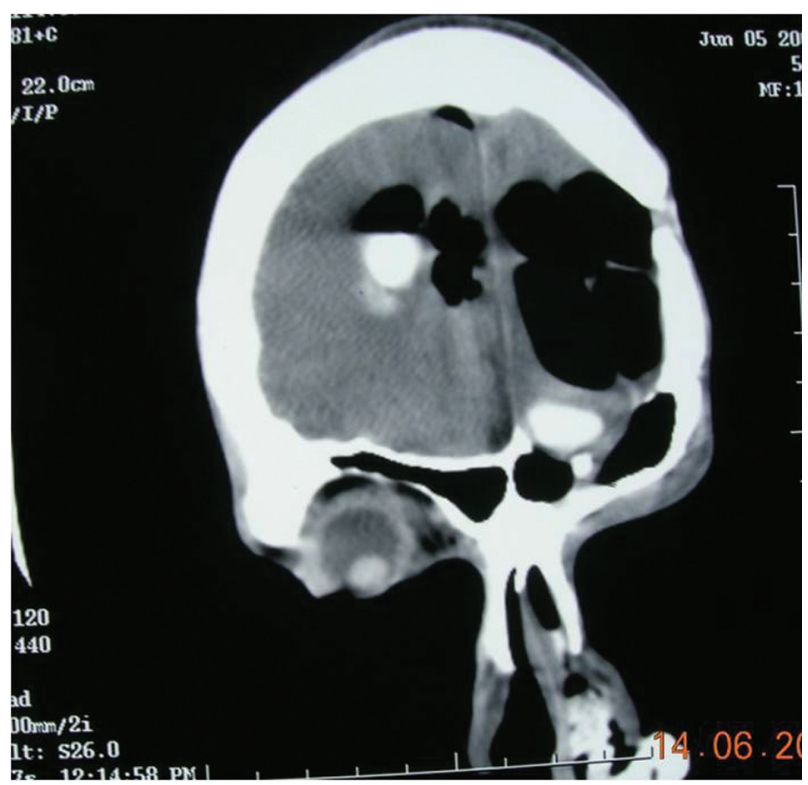

Computed tomography scan showing fracture of the posterior table of the frontal sinus with pneumoencephalus.

safe entry into the frontal sinus. Although image guidance outlines the whole frontal sinus area giving it a higher degree of safety, its cost factor and hence limited availability is a hurdle.

With the advent of computed tomography scans and endoscopes, it has now become possible to open the frontal recess with mucosal preservation, depending on the extent of disease. Several surgeons nowadays combine both the endoscopic and external approaches to address the frontal sinus, resulting in better management. However, the review and analysis of various authors has revealed that only the osteoplastic flap has borne better results as compared with endoscopic approaches in terms of reducing recurrence and need for revision procedures, and therefore remains the gold-standard technique [28].

\section{Conclusion}

Osteoplastic bone flap procedure is one of the most relevant external approaches to frontal sinus surgery even today, which we can advocate for laterally placed frontal sinus pathology, narrow sinus anteroposterior diameter, posterior table fractures or anterior table fractures with deformity, neo-osteogenesis of the frontal recess, etc. While more emphasis is being given to endoscopic approaches in the present era, osteoplastic flap approach still needs to be a part of the teaching curriculum keeping in mind its costeffectiveness, with almost no need for a specialized infrastructure and the relative ease for beginners.
Osteoplastic flap is thus here to stay until the time endoscopic setup and navigation system is widespread in every level of healthcare delivery system.

\section{Financial support and sponsorship \\ Nil.}

\section{Conflicts of interest}

There are no conflicts of interest.

\section{References}

1 Stevenson RS, Guthrie D. A history of otolaryngology. Baltimore, MD: Williams \& Wilkins; 1949;104.

2 Jones NS. Management of frontal sinuses. In: Flint PW, Haughey BH, Lund VJ, Niparko JK, Richardson MA, editors. Cummings otolaryngology head and neck surgery. 5th ed. Philadelphia, PA: Elsevier; 2010;781-784.

3 Silverman JB, Gray ST, Busaba NY. Role of osteoplastic frontal sinus obliteration in the era of endoscopic sinus surgery. Int $\mathrm{J}$ Otolaryngol 2012;2012:501896.

4 Bockmuhl U, Kountakis SE, Senior BA. Wolfgang Draf osteoplastic frontal sinusotomy and reconstruction of frontal defects. In: Kountakis SE, Senior A, Draf W, editors. Frontal sinus stilianos, thieme. New York: Springer; 2005;281-290.

5 Weber R, Draf W, Kahle G, Kind M. Obliteration of the frontal sinus - state of the art and reflections on new materials. Rhinology 1999;37:1-15.

6 Weber R, Draf W, Keerl R, Kahle G, Schinzel S, Thomann S, Lawson W. Osteoplastic frontal sinus surgery with fat obliteration: technique and longterm results using magnetic resonance imaging in 82 operations. Laryngoscope 2000;110:1037-1044

7 Tato JM, Bergaglio OE. (1949) Cirurgia del frontal injerto de grosa. Nueva tecnica (surgery of frontal sinus. Fat grafts: new technique. Otolaryngologica $3: 1$, Oct. 1949) cited according Tato, Sibbald and Bergaglio. Laryngoscope 1954;64:504-521.

8 Rajapaksa SP, Ananda A, Cain T, Oates L, Wormald PJ. The effect of the modified endoscopic Lothrop procedure on the mucociliary clearance of the frontal sinus in an animal model. Am J Rhinol 2004;18:183-187.

9 Wormald PJ, Ananda A, Nair S. The modified endoscopic Lothrop procedure in the treatment of complicated chronic frontal sinusitis. Clin Otolaryngol Allied Sci 2003;28:215-220.

$10 \mathrm{Kim} \mathrm{E}$, Cutler JL Balloon dilatation of the paranasal sinuses: a tool in sinus surgery. Otolaryngol Clin North Am 2009;42:847-856.

11 Ogston A. Trephining the frontal sinus for catarrhal diseases. Men Chron Manchester 1884;1:235.

12 Coakley CG. Frontal sinusitis: diagnosis, treatment, and results. Trans Am Laryngol Rhinol Otol Soc 1905;11:101.

13 Knapp A. The surgical treatment of orbital complications in disease of the nasal accessory sinuses. JAMA 1908;51:299.

14 Lothrop HA. XIV. Frontal sinus suppuration: the establishment of permanent nasal drainage; the closure of external fistulae; epidermization of sinus. Ann Surg 1914;59:937-957.

15 Lynch RC. The technique of a radical frontal sinus operation which has given me the best results. Laryngoscope 1921;31:1.

16 Howarth WG. Operations on the frontal sinus. J Laryngol Otol 1921;36:417-421.

17 Goodale RL, Montgomery WW. Experience with osteoplastic anterior wall approach to the frontal sinus. Arch Otolaryngol 1958;68:271.

18 Hardy JM, Montgomery WW. Osteoplastic frontal sinusotomy: an analysis of 250 operations. Ann Otol Rhinol Laryngol 1976;85(Pt 1):523-532.

19 Ohta N, Suzuki Y, Waki T, Kurakami K, Hinohira Y, et al. Exploring the limits of the endoscopic approach to frontal sinus osteoma. Otolaryngology 2013;3:140.

20 Bignami M, Dallan I, Terranova P, Battaglia P, Miceli S, Castelnuovo P. Frontal sinus osteomas: the window of endonasal endoscopic approach. Rhinology 2007;45:315-320.

21 Erdogan N, Demir U, Songu M, Ozenler NK, Uluç E, Dirim B A prospective study of paranasal sinus osteomas in 1,889 
cases: changing patterns of localization. Laryngoscope 2009;119:2355-2359.

22 Schick B, Steigerwald C, el Rahman el Tahan A, Draf W. The role of endoscopic surgery in the management of frontoethmoid osteomas. Rhinology 2001;39:66-70.

23 Draf W. Endonasal frontal sinus drainage type I-III according to Draf. In: Kountaks S, Seniro B, Draf W, editors. The frontal sinus. 1st ed. New York, NY: Springer; 2005. 219-231.

24 Ledderose GJ, Betz CS, Steleter K, Leunig A. Surgical management of osteoma of the frontal recess and sinus: extending the limits of the endoscopic approach. Eur Arch Otorhinolaryngol 2011;268:525-532.
25 Bigami M, Dallan I, Terranova P, Battaglia P, Miceli S, et al. Frontal sinus osteomas: window of endoscopic approach. Rhinology 2004;42:315-320.

26 Donald PJ, Gluckman J, Rice D. The sinuses. New York, NY: Raven Press 1995;468.

27 Becker DG, Moore D, Lindsey WH, Gross WE, Gross CW Modified transnasal endoscopic Lothrop procedure: further considerations. Laryngoscope 1995;105:1161-1166.

28 Ulualp SO, Carlson TK, Toohill RJ. Osteoplastic flap versus modified endoscopic Lothrop procedure in patients with frontal sinus disease. Am J Rhinol 2000; 14: 21-26. 